\title{
BMJ Open Association between hormone replacement therapy and carpal tunnel syndrome: a nationwide population- based study
}

\author{
Hsien-Chin Tang, ${ }^{1,2}$ Ya-Yun Cheng (D) ,2,3 How-Ran Guo (D) 2,4,5
}

To cite: Tang H-C, Cheng Y-Y, Guo H-R. Association between hormone replacement therapy and carpal tunnel syndrome: a nationwide populationbased study. BMJ Open 2022;12:e055139. doi:10.1136/ bmjopen-2021-055139

- Prepublication history for this paper is available online. To view these files, please visit the journal online (http://dx.doi. org/10.1136/bmjopen-2021055139).

Received 05 July 2021 Accepted 27 October 2021

\section{Check for updates}

(C) Author(s) (or their employer(s)) 2022. Re-use permitted under CC BY-NC. No commercial re-use. See rights and permissions. Published by BMJ.

${ }^{1}$ Department of Family Medicine, Ditmanson Medical Foundation Chia-Yi Christian Hospital, ChiaYi, Taiwan

${ }^{2}$ Department of Environmental and Occupational Health, College of Medicine, National Cheng Kung University, Tainan, Taiwan

${ }^{3}$ Department of Environmental Health, Harvard University T.H. Chan School of Public Health, Boston, Massachusetts, USA ${ }^{4}$ Department of Occupational and Environmental Medicine, National Cheng Kung University Hospital, Tainan, Taiwan

${ }^{5}$ Occupational Safety, Health and Medicine Research Center, National Cheng Kung University, Tainan, Taiwan

Correspondence to

Professor How-Ran Guo;

hrguo@mail.ncku.edu.tw

\section{ABSTRACT}

Objective Carpal tunnel syndrome (CTS) is the most common compressive focal mononeuropathy, and the increased incidence in postmenopausal and pregnant women suggests its association with oestrogen. The objective of this study is to evaluate the relationship between hormone replacement therapy (HRT) and the occurrence of CTS.

Design Population-based case-control study.

Setting Nationwide health insurance programme operated by the government with a near $100 \%$ coverage rate. Participants We identified women $\geq 45$ years old in the Health Insurance Research Database of Taiwan, which contains data on a representative sample of one million enrollees. After exclusion of those who were diagnosed with CTS before the prescription of HRT, a total of 118309 participants were included and followed up for 15 years starting from 1 January 1996. Both HRT and occurrence of CTS were identified using the insurance claims.

Main outcome measures We identified incident patients of CTS and evaluated the association between HRT and CTS by calculating the $\mathrm{OR}$.

Results Of the 4535 participants who developed CTS during the study period, 2334 (51.5\%) were HRT recipients. In participants without CTS, the proportion of HRT recipients was $28.1 \%$, yielding an OR of 2.72 with a $95 \% \mathrm{Cl}$ of 2.56 to 2.88 . After adjustment for age, diabetes, rheumatoid arthritis, hypothyroidism, gout and obesity, the OR of CTS associated with HRT was 2.04 (95\% Cl 1.91 to 2.17). While HRT, diabetes, rheumatoid arthritis and gout had similar effects on CTS across all age groups, hypothyroidism and obesity had different effects on different groups.

Conclusion This study observed a positive association between HRT and CTS, independent of age, diabetes, rheumatoid arthritis, hypothyroidism, gout and obesity. While the ORs of CTS associated with HRT were similar across age groups, those associated with hypothyroidism and obesity were not, indicating effect modifications by age.

\section{INTRODUCTION}

Carpal tunnel syndrome (CTS) is the most common compressive focal mononeuropathy, which is mainly caused by an entrapment of the median nerve in the carpal tunnel at
Strengths and limitations of this study

- The large population enabled us to obtain stable risk estimates and simultaneously adjust for many potential confounding factors.

- The National Health Insurance Research Database (NHIRD) used in this study is a representative sample of the general population in Taiwan and thus provides an unbiased study population.

-While the diagnosis coded in the claims may be tentative in some cases, we included cases with at least three claims to ensure the accuracy of the diagnosis.

- The National Health Insurance of Taiwan has very low co-pay, so patients are unlikely to be hindered from diagnosis or treatment because of financial consideration, which minimised misclassification of cases.

- We were unable to adjust for occupational factors such as repetitive hand use because no such data are available in the NHIRD.

the wrist. ${ }^{1}$ The estimated annual incidence of CTS is about 99 per $100000 .^{2}$ In the USA, the estimated annual medical cost for CTS exceeded 2 billion dollars, mostly paid for surgical releases. ${ }^{3}$ The typical symptoms and signs of CTS included pain, paresthesia and weakness in the median nerve distribution. ${ }^{4}$

Both occupational factors and nonoccupational factors contribute to the occurrence of CTS. Repetitive hand and wrist use, sustained wrist extension and flexion, prolonged wrist or palm pressure, the use of vibratory tools and working in cold temperature are the most common occupational factors. ${ }^{5}$ Common non-occupational factors included female sex, pregnancy, obesity, diabetes, hypothyroidism and rheumatoid arthritis. ${ }^{6}$ A review of literature showed that the most common medical conditions related to CTS were diabetes, hypothyroidism and rheumatoid arthritis. ${ }^{7}$ As both diabetes and hypothyroidism are diseases of the endocrine system and the occurrence of CTS was found 
to be related to pregnancy and menopause, ${ }^{8}$ it is reasonable to speculate that there is an association between female reproductive hormones and the occurrence of CTS.

Menopause is often associated with irritating vasomotor symptoms such as hot flushes, which are attributable to decreases in oestrogen levels, ${ }^{9}$ and hormone replacement therapy (HRT) is the most effective treatment for these symptoms. HRT generally includes oestrogen preparations, ${ }^{10}$ and progesterone regimen should be prescribed to reduce the risk of endometrial hyperplasia and cancer, except in women who have undergone a hysterectomy. ${ }^{112}$ After evaluating the benefits and harms of HRT for postmenopausal women, the US Preventive Services Task Force recently released a statement asserting that they do not recommend the use of HRT for the primary prevention of chronic conditions. ${ }^{13}$

If female reproductive hormones can affect the occurrence of CTS, HRT should have an effect on CTS. However, studies on association between HRT and CTS are limited, and CTS was not among the conditions evaluated by the US Preventive Services Task Force. A study at a hospital in the USA observed a higher risk of CTS in women receiving HRT, with an OR of 2.4. ${ }^{14}$ Another study in the USA observed a higher risk of CTS in women receiving HRT, with an OR of 1.8 after adjusting for other risk factors. ${ }^{6}$ However, a study followed six perimenopausal women who had CTS and found improvements in menopausal symptom scores and pain scores after 6 months of HRT. ${ }^{15}$ Nonetheless, a study in the UK with 3391 CTS patients (including 2444women) found that CTS was not associated with HRT or contraceptive pill use. ${ }^{16}$ There were limited number of studies, and the results were inconsistent. Three of the four previous studies used cross-sectional data and thus could not determine the temporal relationship between HRT and CTS. The study that could determine the temporal relationship included six perimenopausal women only and examined the effects of HRT on existing CTS, not the effects of HRT on the occurrence of CTS. Therefore, we conducted a study to evaluate the association between HRT and the occurrence of CTS using data from the National Health Insurance (NHI) in Taiwan.

\section{METHODS}

\section{Data sources}

The NHI was implemented in Taiwan on 1 March 1995 and covers almost all of the 23 million residents. We obtained data on one million randomly selected enrollees from the National Health Insurance Research Database (NHIRD). The data covers a period of 15 years, starting from 1 January 1996, and there were 483147 (48.3\%) females in the dataset.

\section{Study design}

Because the median and mean ages of menopause are both around 51 years old, ${ }^{17} 18$ we included women $\geq 45$

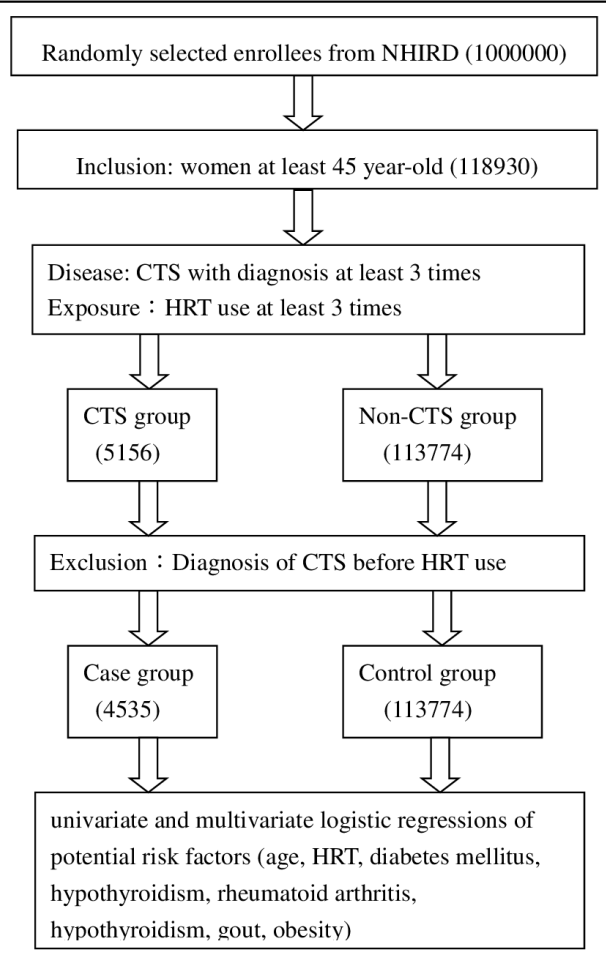

Figure 1 Flow chart of the study of the association between hormone replacement therapy (HRT) and carpal tunnel syndrome (CTS). NHIRD, National Health Insurance Research Database.

years old and divided them into five groups: $45-49,50-54$, $55-59,60-64$ and $\geq 65$ years old.

We used the International Classification of Diseases, Ninth Revision, Clinical Modification (ICD-9) code 354.0 to identify patients with CTS. We defined patients who were diagnosed with CTS in at least three ambulatory care visits as cases of CTS and others as controls. Likewise, we identified patients with the prescription of oestrogen or estradiol in at least three ambulatory care visits as HRT recipients. Patients with a diagnosis of CTS before receiving HRT were excluded from the analyses (figure 1).

The potential risk factors for CTS we evaluated in this study included diabetes (ICD-9 code 250 and A-code A181), rheumatoid arthritis (ICD-9 code 714 and A-code A430), gout (ICD-9 code 274 and A-code A189), hypothyroidism (ICD-9 codes 243 and 244 and A-code A180) and obesity (ICD-9 code 278 and A-code A183). Again, patients with the diagnosis in at least three ambulatory care visits were defined as having the risk factor.

\section{Statistical analysis}

We used $\chi^{2}$ tests to evaluate the differences in the proportion of HRT recipients in both CTS cases and controls across different age groups. To identify independent risk factors for CTS, we first applied univariate logistic regressions to calculate the OR and the associated $95 \%$ CI for each risk factor and to evaluate its effects. Then, we constructed a multivariate logistic model that included 
all the potential risk factors identified in the univariate regressions. The goodness of fit of models was evaluated by the Hosmer-Lemeshow test. Because HRT is related to age, we conducted stratified analyses to evaluate potential effect modifications by age, using multivariate regression models that include all potential risk factors other than age. We used the Cochran-Armitage trend test to evaluate the trends of risks across age groups. All the data analyses were performed using SAS V.9.3 (SAS) and SPSS V.17.0 (SPSS), and all statistical tests were performed at a twosided significance level of 0.05 .

\section{Patient and public involvement}

Patients or the public were not involved in the design, or conduct, or reporting, or dissemination plans of this research.

\section{RESULTS}

A total of 15617 participants were identified as cases of CTS from the one million randomly selected enrollees, yielding an estimated prevalence of $1.6 \%$ among all ages and both sexes. Of the 118309 women $\geq 45$ years old, 5156 were identified as cases of CTS, yielding an estimated prevalence of $4.34 \%$. A total of 102374 participants were identified as HRT recipients, yielding an estimated prevalence of $10.3 \%$. After excluding those who had been diagnosed with CTS before being prescribed oestrogen, we included 4535 cases of CTS in the data analyses.

Overall, the proportion of HRT recipients among CTS cases $\geq 45$ years old was $51.5 \%$, and it was $28.1 \%$ in the controls. This yielded an OR of 2.72 (95\% CI 2.56 to 2.88). When broken down by age, the OR increased with age. Specifically, the OR was 2.01 (95\% CI 1.82 to 2.21) in women $45-49$ years old, 2.04 (95\% CI 1.79 to 2.33 ) in women 50-54 years old, 2.07 (95\% CI 1.78 to 2.39 ) in women 55-59 years old, 2.13 (95\% CI 1.78 to 2.56 ) in women 60-64 years old and 2.35 (95\% CI 1.92 to 2.88 ) in women $\geq 65$ years old (table 1$)$.

In the univariate logistic regression analysis, we also identified obesity $(\mathrm{OR}=2.56)$, rheumatoid arthritis $(\mathrm{OR}=1.90)$, gout $(\mathrm{OR}=1.64)$, hypothyroidism $(\mathrm{OR}=1.50)$ and diabetes $(\mathrm{OR}=1.21)$ as potential risk factors for CTS. Results of multivariate logistic regression analyses showed that HRT was an independent risk factor, with an OR of 2.04 (95\% CI 1.91 to 2.17) after adjusting for other potential risk factors, including age, diabetes, rheumatoid arthritis, hypothyroidism, gout and obesity (table 2). The adjusted OR associated with other independent risk factors for CTS was 1.21 for diabetes (95\% CI 1.13 to 1.29), 1.85 for rheumatoid arthritis (95\% CI 1.70 to 2.00), 1.76 for obesity (95\% CI 1.41 to 2.18), 1.52 for gout (95\% CI 1.40 to 1.64 ) and 1.19 for hypothyroidism (95\% CI 1.04 to $1.37)$. An age $\geq 55$ years appeared to be a protective factor, with an adjusted OR of 0.45 (95\% CI 0.43 to 0.48 ). The Hosmer-Lemeshow test for the goodness of fit of the final multivariate model was significant $(\mathrm{p}<0.01)$.

When we performed stratified analyses by age, we found that HRT was an independent risk factor for CTS in all age groups and that the risk increased with age. Specifically, the adjusted OR was 1.83 (95\% CI 1.66 to 2.02) in women 45-49 years old, 1.84 (95\% CI 1.60 to 2.10) in women 50-54 years old, 1.88 (95\% CI 1.62 to 2.19 ) in women $55-59$ years old, 1.90 (95\% CI 1.58 to 2.29) in women 60-64 years old and 1.93 (95\% CI 1.57 to 2.37 ) in women $\geq 65$ years old (table 3 ). Rheumatoid arthritis and gout were independent risk factors in all age groups. While diabetes was associated with an increased risk of CTS in all age groups, the increase did not reach

Table 1 The relationship of carpal tunnel syndrome and hormone replacement therapy (HRT) in women in different age groups

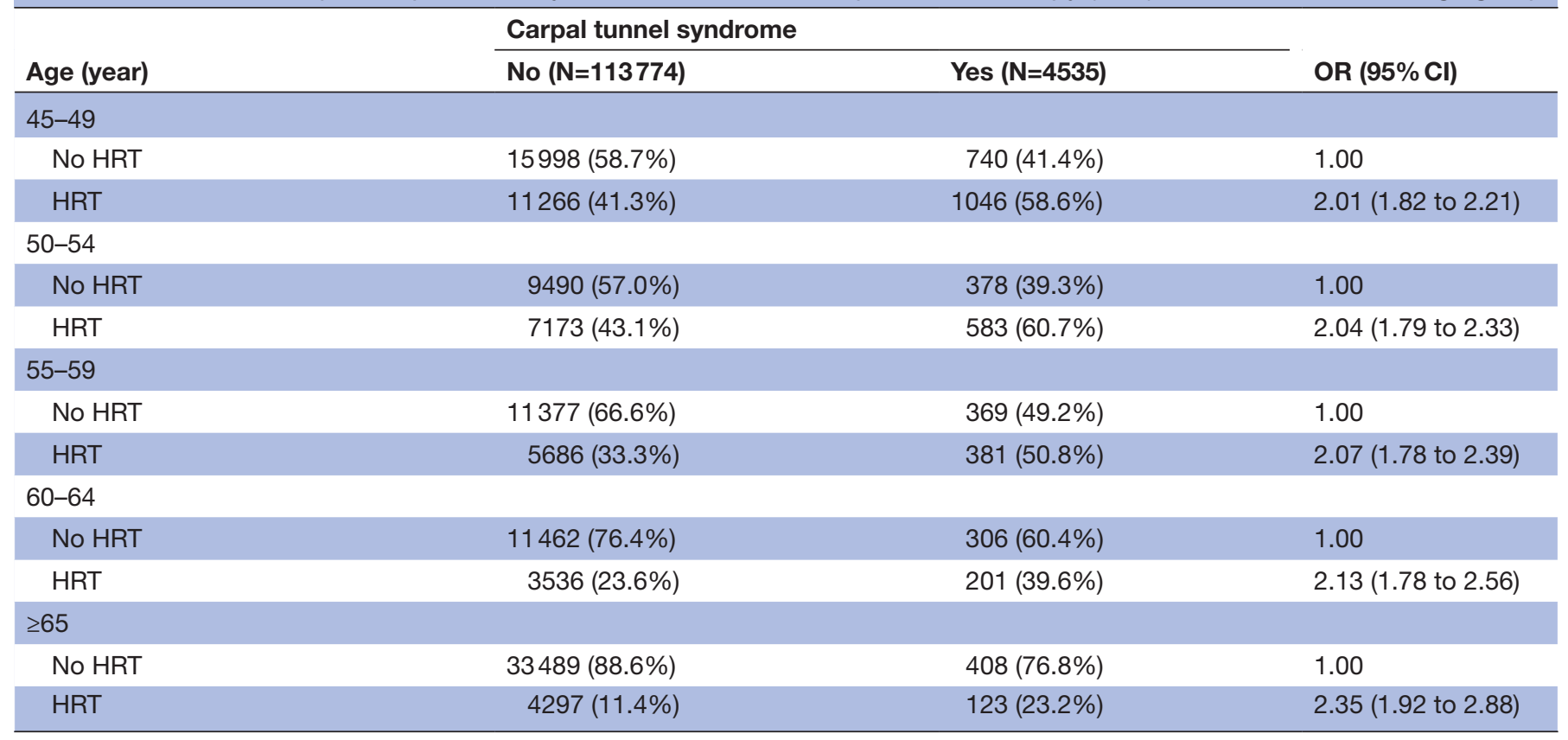


Table 2 Logistic regression analyses of potential risk factors for carpal tunnel syndrome

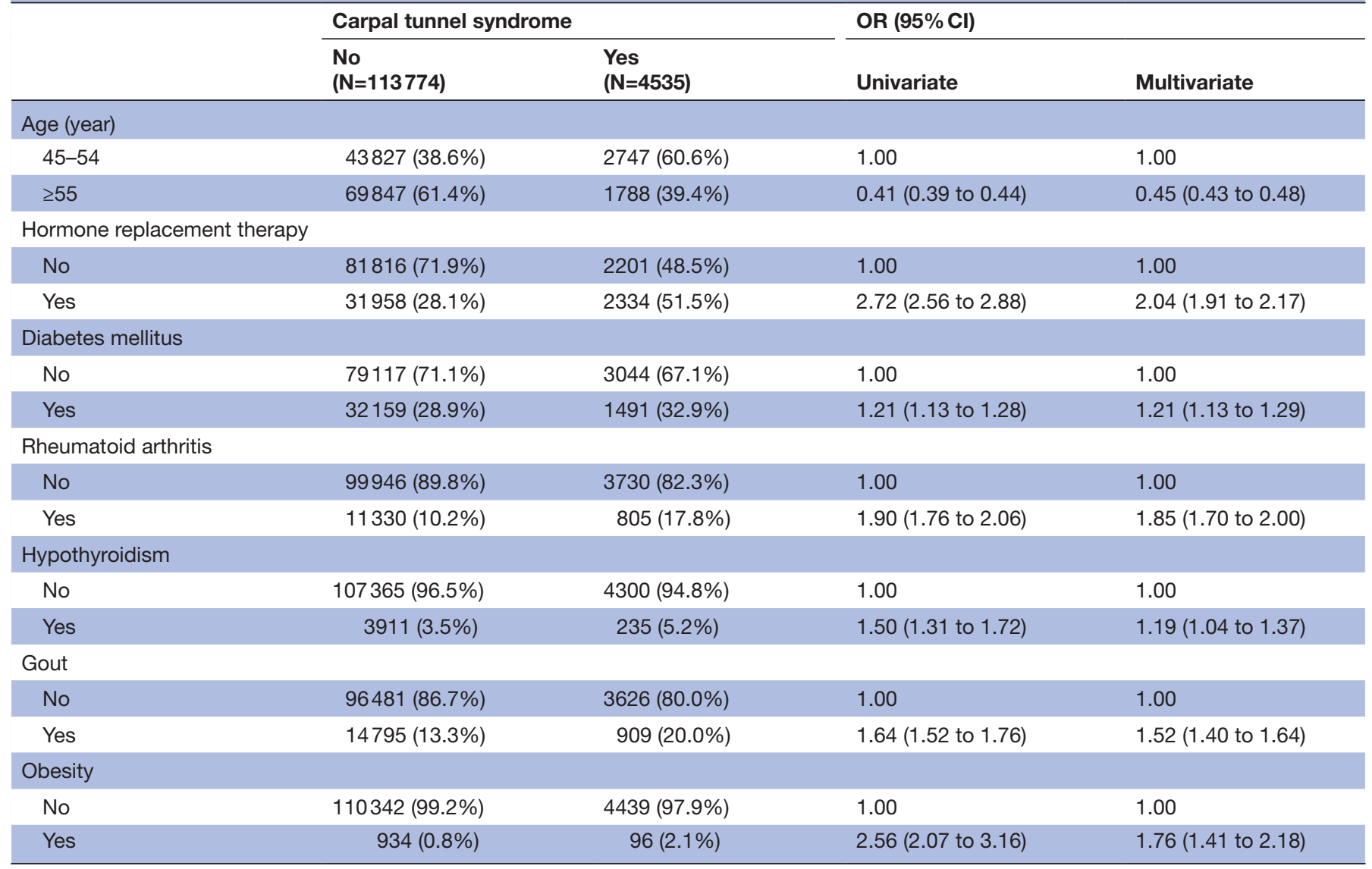

statistical significance in the age group 60-64 years old. Likewise, obesity was associated with an increased risk of CTS in all age groups, but the increase in the risk decreased with age and did not reach statistical significance in the two age groups above 59 years old. Hypothyroidism was not a significant independent risk factor for CTS in women between 50 and 64 years of age. The Cochran-Armitage trend test showed a significant trend $(\mathrm{p}<0.001)$ in the increases of risks for CTS associated with HRT with increases in age.

\section{DISCUSSION}

\section{Prevalence of CTS}

The prevalence of CTS in the general population varies substantially across studies, depending on factors including the diagnostic tool, survey method, population, etc. For example, in a study on 2466 subjects in southern Sweden, the prevalence of clinically confirmed patients of CTS was $3.8 \%$, electrophysiologically confirmed patients was $4.9 \%$, and both clinically and electrophysiologically confirmed patients was 2.7\% ${ }^{19}$ The 1988 National Health Interview Survey in the USA found that the prevalence of self-reported cases of CTS was $1.55 \% .^{20} \mathrm{~A}$ study using various methods on 715 subjects in the Netherlands found that the prevalence was $5.8 \%$ in women and $0.6 \%$ in men. ${ }^{21}$
In this study, we identified patients with a diagnosis of CTS for at least three ambulatory visits as confirmed cases. Of the 118309 women $\geq 45$ years old, 5156 such patients were identified, yielding an estimated prevalence of $4.34 \%$, which is close to the reported prevalence of clinically confirmed patients of CTS, $3.8 \%$, of a study in southern Sweden.

\section{Possible pathogenesis of CTS associated with HRT}

While most cases of CTS are idiopathic, the pathogenesis of such cases is thought to be related to the decreased size of the carpal canal (the container) or the increased volume of the contents within the canal. ${ }^{22-24}$ For example, joint abnormalities caused by inflammatory arthritis and abnormalities of the shape or position of the bones caused by fractures are both abnormalities of the container that may lead to CTS. Metabolic tenosynovitis caused by diabetes, abnormalities of fluid distribution caused by pregnancy or hypothyroidism and haematoma caused by trauma are examples of abnormalities of contents that may lead to CTS. ${ }^{23}$

We found that HRT was an independent risk factor for CTS, which was observed in all women $\geq 45$ years old. In CTS patients, the most common histological finding is non-inflammatory fibrosis of the subsynovial connective tissue. ${ }^{25}{ }^{26}$ Hormonal fluctuations and fluid accumulation are generally believed to be the pathogenesis of the 
Table 3 Stratified multivariate logistic regression analyses of potential risk factors for carpal tunnel syndrome (CTS) by age

\begin{tabular}{|c|c|c|c|}
\hline & Non-CTS & CTS & OR $(95 \% \mathrm{Cl})$ \\
\hline \multicolumn{4}{|l|}{ 45-49 years old } \\
\hline HRT & $11266(41.3 \%)$ & 1046 (58.6\%) & 1.83 (1.66 to 2.02 ) \\
\hline Diabetes mellitus & 5069 (18.9\%) & $433(24.2 \%)$ & 1.21 (1.08 to 1.36$)$ \\
\hline Rheumatoid arthritis & $1621(6.0 \%)$ & $221(12.4 \%)$ & 1.86 (1.60 to 2.17$)$ \\
\hline Hypothyroidism & $1005(3.7 \%)$ & 95 (5.3\%) & 1.24 (1.00 to 1.55$)$ \\
\hline Gout & $2261(8.4 \%)$ & 259 (14.5\%) & $1.52(1.32$ to 1.76$)$ \\
\hline Obesity & $318(1.2 \%)$ & $41(2.3 \%)$ & 1.55 (1.10 to 2.17$)$ \\
\hline \multicolumn{4}{|l|}{$50-54$ years old } \\
\hline HRT & $7173(43.1 \%)$ & $583(60.7 \%)$ & 1.84 (1.60 to 2.10$)$ \\
\hline Diabetes mellitus & $4446(27.0 \%)$ & $313(32.6 \%)$ & 1.18 (1.02 to 1.36$)$ \\
\hline Rheumatoid arthritis & $1402(8.5 \%)$ & $188(19.6 \%)$ & 2.25 (1.89 to 2.67 ) \\
\hline Hypothyroidism & 740 (4.5\%) & $51(5.3 \%)$ & 0.97 (0.73 to 1.31$)$ \\
\hline Gout & 2003 (12.2\%) & $186(19.4 \%)$ & 1.40 (1.18 to 1.67$)$ \\
\hline Obesity & $201(1.2 \%)$ & $28(2.9 \%)$ & 2.08 (1.38 to 3.13$)$ \\
\hline \multicolumn{4}{|l|}{ 55-59 years old } \\
\hline HRT & $5686(33.3 \%)$ & $381(50.8 \%)$ & 1.88 (1.62 to 2.19$)$ \\
\hline Diabetes mellitus & 5457 (32.3\%) & $296(39.5 \%)$ & 1.23 (1.05 to 1.43$)$ \\
\hline Rheumatoid arthritis & $1794(10.6 \%)$ & $158(21.1 \%)$ & 1.93 (1.60 to 2.32 ) \\
\hline Hypothyroidism & 2449 (14.5\%) & $162(21.6 \%)$ & 0.96 (0.67 to 1.36$)$ \\
\hline Gout & 695 (4.1\%) & $34(4.5 \%)$ & 1.33 (1.10 to 1.60$)$ \\
\hline Obesity & $171(1.0 \%)$ & $17(2.3 \%)$ & 1.81 (1.08 to 3.02 ) \\
\hline \multicolumn{4}{|l|}{ 60-64 years old } \\
\hline HRT & $3536(23.6 \%)$ & 201 (39.6\%) & 1.90 (1.58 to 2.29$)$ \\
\hline Diabetes mellitus & $5293(35.8 \%)$ & $218(43.0 \%)$ & 1.18 (0.98 to 1.42$)$ \\
\hline Rheumatoid arthritis & 1749 (11.8\%) & $107(21.1 \%)$ & 1.67 (1.33 to 2.08 ) \\
\hline Hypothyroidism & $522(3.5 \%)$ & $26(5.1 \%)$ & 1.27 (0.85 to 1.91$)$ \\
\hline Gout & 2400 (16.2\%) & $151(29.8 \%)$ & 1.91 (1.57 to 2.34$)$ \\
\hline Obesity & $126(0.9 \%)$ & $7(1.4 \%)$ & 1.22 (0.56 to 2.65$)$ \\
\hline \multicolumn{4}{|l|}{$\geq 65$ years old } \\
\hline HRT & 4297 (11.4\%) & $123(23.2 \%)$ & 1.93 (1.57 to 2.37 ) \\
\hline Diabetes mellitus & 11894 (32.8\%) & $231(43.5 \%)$ & 1.36 (1.14 to 1.63$)$ \\
\hline Rheumatoid arthritis & $4764(13.1 \%)$ & $131(24.7 \%)$ & 1.82 (1.48 to 2.23$)$ \\
\hline Hypothyroidism & 949 (2.6\%) & 29 (5.5\%) & 1.82 (1.24 to 2.67$)$ \\
\hline Gout & $5682(15.7 \%)$ & $151(28.4 \%)$ & 1.78 (1.46 to 2.16$)$ \\
\hline Obesity & $118(0.3 \%)$ & $3(0.6 \%)$ & 1.19 (0.37 to 3.80$)$ \\
\hline
\end{tabular}

HRT, hormone replacement therapy.

development of CTS symptoms in pregnant women. ${ }^{27}$ In postmenopausal women, some studies demonstrated that fluctuation of the oestrogen level was associated with idiopathic CTS, although the pathogenesis remains unclear. ${ }^{8}$

Estrogens have some anti-inflammatory properties, and increased levels of some inflammatory cytokines such as interleukin 1 (IL-1), IL-6 and tumour necrosis factoralpha are noted after menopause. ${ }^{28}$ Therefore, decreases in the oestrogen level, as in menopausal women who require HRT, may lead to high levels of cytokines, which may in turn cause cellular proliferation, angiogenesis, increased capillary permeability, edematous changes and then fibrosis. ${ }^{29}$ When these changes occur in the carpal tunnel, they might contribute to the development of CTS.

It was also postulated that the stimulations of tenosynovial tissue may cause CTS. Receptors of oestrogen (ER) and progesterone have been found in the transverse carpal ligament and flexor tenosynovium. ${ }^{30}$ A study found an increase of the expressions of ER in tenosynovial tissue histologically and immunohistochemically in patients 
with CTS. ${ }^{31}$ HRT might upregulate ER in the transverse carpal ligament and flexor tenosynovium and thus increase fibroblasts and synovial lining cells in the tenosynovial tissue, which increases the risk of CTS. A study found prenatal and postnatal sex hormones played some roles in CTS development in the context of ER activation and the pattern of fat distribution, ${ }^{32}$ which supports the argument of an association between HRT and CTS. However, the pathogenesis of the association remains unclear and might be different from that of idiopathic CTS in postmenopausal women.

\section{Other potential risk factors for CTS}

Diabetes mellitus is one of the most common risk factors for CTS. A recent study proposed that the ischaemic damage and neoangiogenesis in diabetes patients contribute to the occurrence of CTS. The increased vascular endothelial growth factor expression and neovascularisation within the subsynovial connective tissue are also believed to be contributing factors, as in diabetic nephropathy and retinopathy. ${ }^{33}$ In multivariate analyses, we found that diabetes was associated with an increased risk of CTS. When we divided the participants into five age groups, the ORs were similar across all age groups (fluctuating between 1.18 and 1.36), although the OR did not reach statistical significance in the 60 to 64 year-old group, most likely because of the smaller case number (the smallest of all groups).

Rheumatoid arthritis has also been identified as a risk factor for CTS. ${ }^{6}$ The pathogenesis of CTS in rheumatoid arthritis patients is believed to be a result of increasing intracarpal tunnel pressure caused by tenosynovitis around the transverse carpal ligament and flexor tendons. ${ }^{34}$ In multivariate analyses, we found that rheumatoid arthritis was associated with an increased risk $(\mathrm{OR}=1.85, \mathrm{p}<0.001)$. When we divided the participants into five age groups, the ORs were similar across all age groups (fluctuating between 1.67 and 2.25), and all reached statistical significance.

The mechanism of neuropathy in patients with hypothyroidism is unclear. Abnormalities of fluid distribution is a likely aetiology CTS. ${ }^{23}$ The deposition of mucopolysaccharides or mucinous material on the median nerve might also contribute to its occurrence. ${ }^{35}$ In multivariate analyses, we found that hypothyroidism was associated with an overall OR of $1.19(\mathrm{p}=0.013)$. When we divided the participants into five age groups, the OR showed a U shape dose-response relationship with age and reached statistical significance only in the youngest and the oldest groups. This implies that multiple factors are involved.

Gouty tophi can lead to the non-traumatic compression of the median nerve in the carpal tunnel, causing mechanical or neurological symptoms. CTS secondary to gout is uncommon except in the cases with spaceoccupying lesions caused by tophi. ${ }^{36}$ Except for the median nerve, tophi may also involve the flexor tendons inside the carpal tunnel. ${ }^{37}$ In multivariate analyses, we found that gout was associated with an increased risk
$(\mathrm{OR}=1.52, \mathrm{p}<0.001)$. When we divided the participants into five age groups, the ORs were similar across all age groups (fluctuating between 1.33 and 1.91), all reaching statistical significance.

Our findings confirm that obesity is an independent risk factor for CTS. ${ }^{6}$ It may be due to the increased fat tissue within the carpal tunnel and increased hydrostatic pressure throughout the carpal tunnel. ${ }^{38}$ In multivariate analyses, we found that obesity was associated with an increased risk $(\mathrm{OR}=1.76, \mathrm{p}<0.001)$. When we divided the participants into five age groups, the OR showed an inversed $U$ shape dose-response relationship with age and did not reach statistical significance in the two oldest groups. This implies that multiple factors are involved, although the smaller case numbers in the two oldest age groups might also contribute to the results.

\section{Strength and limitations}

The large population in this study enabled us to obtain stable risk estimates and simultaneously adjust for many potential confounding factors. We were also able to conduct stratified analyses. In addition, the near 100\% coverage of the NHIRD provides an unbiased study population, and therefore the results are representative of the whole country. Because we used the claim data from an insurance programme with a 500 -fold fine on treatment deemed to be unnecessary, both overdiagnosis of CTS and over-use of HRT are unlikely. While the diagnosis coded in the claims may be tentative in some cases, we included cases with at least three claims. On the other hand, the NHI has a nearly $100 \%$ coverage and a very low co-pay, less than US $\$ 20$. Therefore, patients are unlikely to be hindered from diagnosis or treatment because of financial consideration, and so misclassification of cases was minimum in our study.

Nonetheless, our study had some limitations. In particular, CTS is a common occupational disease, but no data on occupation risk factors such as repetitive hand use are available in the NHIRD. Although we were unable to adjust for occupational factors, we did observe the association in women more than 60 years old, and most women in Taiwan have retired by this age, not to mention that the association was also observed in the oldest age group ( $\geq 65$ years). As in all non-experimental studies, the associations observed in our study are not necessarily causal relationships.

We defined patients who were diagnosed withCTS in at least three ambulatory care visits as cases of CTS, and this is a common approach applied by studies using data from the NHIRD. ${ }^{39-41}$ In Taiwan, the diagnosis of CTS made in the first ambulatory visit may be tentative in some cases, and laboratory tests such as nerve conduction study and electromyography are arranged. In such cases, test results are usually available in the second visit. Therefore, when the diagnosis code has been put in the claims for three times, it is safe to say the diagnosis is confirmed. Otherwise, the diagnosis will be changed in the second or third visit. In fact, this is a relatively secure approach, because 
some of such studies defined CTS on the basis of just two, ${ }^{42}$ or even one visit. ${ }^{4344}$

\section{CONCLUSION}

We observed an approximately twofold increase in the prevalence of CTS in female HRT recipient $\geq 45$ years old. In addition, we observed the increase in all age groups and found that it was independent of most risk factors that have been recognised, including diabetes, rheumatoid arthritis, hypothyroidism, gout and obesity. While these factors were also found to be associated with CTS in our study, we found that hypothyroidism and obesity had different effects on different age groups, which should be a novel finding. Further studies are needed to identify the underlying mechanism, so that this side effect of HRT can be minimised.

Acknowledgements We thank the National Health Insurance programme in Taiwan for providing the established database used in our study. The Occupational Safety, Health and Medicine Research Centre of the National Cheng Kung University were supported in part by the Ministry of Labour of Taiwan, R.O.C.

Contributors All authors contributed to the study design (H-CT, $\mathrm{Y}-\mathrm{YC}$ and $\mathrm{H}-\mathrm{RG}$ ). $\mathrm{H}-\mathrm{RG}$ led all aspects of the study. $\mathrm{H}-\mathrm{CT}$ was responsible for the first draft of the manuscript. $\mathrm{H}-\mathrm{CT}$ and $\mathrm{Y}-\mathrm{YC}$ conducted the analysis. All authors (H-CT, $\mathrm{Y}-\mathrm{YC}$ and $\mathrm{H}-$ $\mathrm{RG}$ ) participated in critical revisions of the manuscript, read and approved the final manuscript. H-RG is responsible for the overall content as the guarantor.

Funding The authors have not declared a specific grant for this research from any funding agency in the public, commercial or not-for-profit sectors.

Competing interests None declared.

Patient and public involvement Patients and/or the public were not involved in the design, or conduct, or reporting, or dissemination plans of this research.

Patient consent for publication Not applicable.

Ethics approval This study has been reviewed and approved by the Institutional Review Boards of the Ditmanson Medical Foundation Chia-Yi Christian Hospital (approval No. 104068).

Provenance and peer review Not commissioned; externally peer reviewed.

Data availability statement Data are available on reasonable request. All the data used in this study are available from the Taiwanese government after approval of the application.

Open access This is an open access article distributed in accordance with the Creative Commons Attribution Non Commercial (CC BY-NC 4.0) license, which permits others to distribute, remix, adapt, build upon this work non-commercially, and license their derivative works on different terms, provided the original work is properly cited, appropriate credit is given, any changes made indicated, and the use is non-commercial. See: http://creativecommons.org/licenses/by-nc/4.0/.

\section{ORCID iDs}

Ya-Yun Cheng http://orcid.org/0000-0003-2571-4707

How-Ran Guo http://orcid.org/0000-0003-3343-3446

\section{REFERENCES}

1 Patterson JD, Simmons BP. Outcomes assessment in carpal tunnel syndrome. Hand Clin 2002;18:359-63.

2 Stevens JC, Sun S, Beard CM, et al. Carpal tunnel syndrome in Rochester, Minnesota, 1961 to 1980. Neurology 1988;38:134-8.

3 Falkiner S, Myers S. When exactly can carpal tunnel syndrome be considered work-related? ANZ J Surg 2002;72:204-9.

4 Report of the Quality Standards Subcommittee of the American Academy of Neurology. Practice parameter for carpal tunnel syndrome (Summary statement) [RETIRED]. Neurology 1993;43:2406-9.
5 Barcenilla A, March LM, Chen JS, et al. Carpal tunnel syndrome and its relationship to occupation: a meta-analysis. Rheumatology 2012;51:250-61.

6 Solomon DH, Katz JN, Bohn R, et al. Nonoccupational risk factors for carpal tunnel syndrome. J Gen Intern Med 1999;14:310-4.

7 van Dijk MAJ, Reitsma JB, Fischer JC, et al. Indications for requesting laboratory tests for concurrent diseases in patients with carpal tunnel syndrome: a systematic review. Clin Chem 2003;49:1437-44.

8 Kaplan Y, Kurt SG, Karaer H. Carpal tunnel syndrome in postmenopausal women. J Neurol Sci 2008;270:77-81.

9 Abdi F, Mobedi H, Mosaffa N, et al. Hormone therapy for relieving postmenopausal vasomotor symptoms: a systematic review. Arch Iran Med 2016;19:141-6.

10 Baker VL. Alternatives to oral estrogen replacement. transdermal patches, percutaneous gels, vaginal creams and rings, implants, other methods of delivery. Obstet Gynecol Clin North Am 1994;21:271-97.

11 Jurgens RW, Downey LJ, Abernethy WD, et al. A comparison of circulating hormone levels in postmenopausal women receiving hormone replacement therapy. Am J Obstet Gynecol 1992;167:459-60.

12 Clisham PR, Cedars MI, Greendale G, et al. Long-term transdermal estradiol therapy: effects on endometrial histology and bleeding patterns. Obstet Gynecol 1992;79:96-201.

13 US Preventive Services Task Force, Grossman DC, Curry SJ, et al. Hormone therapy for the primary prevention of chronic conditions in postmenopausal women: US preventive services Task force recommendation statement. JAMA 2017;318:2224-33.

14 Dieck GS, Kelsey JL. An epidemiologic study of the carpal tunnel syndrome in an adult female population. Prev Med 1985;14:63-9.

15 Hall GM, Spector TD, Studd JW. Carpal tunnel syndrome and hormone replacement therapy. BMJ 1992;304:382.

16 Geoghegan JM, Clark DI, Bainbridge LC, et al. Risk factors in carpal tunnel syndrome. J Hand Surg Br 2004;29:315-20.

17 Bromberger JT, Matthews KA, Kuller LH, et al. Prospective study of the determinants of age at menopause. Am J Epidemiol 1997;145:124-33.

18 Kruszyńska A, Słowińska-Srzednicka J. Anti-Müllerian hormone (AMH) as a good predictor of time of menopause. Prz Menopauzalny 2017;16:47-50.

19 Atroshi I, Gummesson C, Johnsson R, et al. Prevalence of carpal tunnel syndrome in a general population. JAMA 1999;282:153-8.

20 Tanaka S, Wild DK, Seligman PJ, et al. The US prevalence of selfreported carpal tunnel syndrome: 1988 National health interview survey data. Am J Public Health 1994;84:1846-8.

21 de Krom MC, Knipschild PG, Kester AD, et al. Carpal tunnel syndrome: prevalence in the general population. J Clin Epidemiol 1992;45:373-6.

22 Shum C, Parisien M, Strauch RJ, et al. The role of flexor tenosynovectomy in the operative treatment of carpal tunnel syndrome. J Bone Joint Surg Am 2002;84:221-5.

23 Chammas M, Boretto J, Burmann LM, et al. Carpal tunnel syndrome - Part I (anatomy, physiology, etiology and diagnosis). Rev Bras Ortop 2014;49:429-36.

24 Aboonq MS. Pathophysiology of carpal tunnel syndrome. Neurosciences 2015;20:4-9.

25 Ettema AM, Amadio PC, Zhao C, et al. A histological and immunohistochemical study of the subsynovial connective tissue in idiopathic carpal tunnel syndrome. J Bone Joint Surg Am 2004;86:1458-66.

26 Gingery A, Yang T-H, Passe SM, et al. TGF- $\beta$ signaling regulates fibrotic expression and activity in carpal tunnel syndrome. J Orthop Res 2014;32:1444-50.

27 Zyluk A. Carpal tunnel syndrome in pregnancy: a review. Pol Orthop Traumatol 2013;78:223-7.

28 Pfeilschifter J, Köditz R, Pfohl M, et al. Changes in proinflammatory cytokine activity after menopause. Endocr Rev 2002;23:90-119.

29 Freeland AE, Tucci MA, Barbieri RA, et al. Biochemical evaluation of serum and flexor tenosynovium in carpal tunnel syndrome. Microsurgery 2002;22:378-85.

30 Toesca A, Pagnotta A, Zumbo A, et al. Estrogen and progesterone receptors in carpal tunnel syndrome. Cell Biol Int 2008;32:75-9.

$31 \mathrm{Kim}$ JK, Hann HJ, Kim MJ, et al. The expression of estrogen receptors in the tenosynovium of postmenopausal women with idiopathic carpal tunnel syndrome. J Orthop Res 2010;28:1469-74.

32 Kasielska-Trojan A, Sitek A, Antoszewski B. Second to fourth digit ratio (2D:4D) in women with carpal tunnel syndrome. Early Hum Dev 2019;137:104829.

33 Deger AN, Deger H, Taser F. The role of neoangiogenesis and vascular endothelial growth factor in the development of carpal 
tunnel syndrome in patients with diabetes. Niger $J$ Clin Pract 2016;19:189-95.

34 Lee K-H, Lee C-H, Lee B-G, et al. The incidence of carpal tunnel syndrome in patients with rheumatoid arthritis. Int $\mathrm{J}$ Rheum Dis 2015;18:52-7.

35 Karne SS, Bhalerao NS. Carpal tunnel syndrome in hypothyroidism. $J$ Clin Diagn Res 2016;10:36-8.

$36 \mathrm{Kim} \mathrm{H-S}$. Carpal tunnel syndrome caused by tophaceous gout. Korean J Intern Med 2014;29:544-5.

37 Sikkandar MF, Sapuan J, Singh R, et al. Gouty wrist arthritis causing carpal tunnel syndrome--a case report. Med J Malaysia 2012;67:333-4.

38 Boz C, Ozmenoglu M, Altunayoglu V, et al. Individual risk factors for carpal tunnel syndrome: an evaluation of body mass index, wrist index and hand anthropometric measurements. Clin Neurol Neurosurg 2004;106:294-9.

39 Tseng C-H, Liao C-C, Kuo C-M, et al. Medical and non-medical correlates of carpal tunnel syndrome in a Taiwan cohort of one million. Eur J Neurol 2012;19:91-7.
40 Chang Y-C, Chiang J-H, Lay I-S, et al. Increased risk of coronary artery disease in people with a previous diagnosis of carpal tunnel syndrome: a nationwide retrospective population-based case-control study. Biomed Res Int 2019;2019:1-8.

41 Yang C, Chen HH, Lee MC. Risk factors of carpal tunnel syndrome in Taiwan: a population-based cohort study. Ann Plast Surg 2021.

42 Chiu Y-H, Yeh K-C, Pan S-L. Increased risk of carpal tunnel syndrome in people with spinal cord injury: a nationwide longitudinal follow-up study. Arch Phys Med Rehabil 2021. doi:10.1016/j.apmr.2021.07.804. [Epub ahead of print: 20 Aug 2021].

43 Wang J-S, Chen W-S, Lin C-L, et al. Risk of carpal tunnel syndrome after parathyroidectomy in patients with end-stage renal disease: a population-based cohort study in Taiwan. Medicine 2020;99:e20313.

44 Lin S-Y, Lin C-L, Hsu W-H, et al. Risk of idiopathic peripheral neuropathy in end-stage renal disease: a population-based cohort study. Int J Clin Pract 2021;75:e13641. 